University of Nebraska - Lincoln

DigitalCommons@University of Nebraska - Lincoln

Effects of combat deployment on risky and self-destructive behavior among active duty military personnel

\author{
Cynthia J. Thomsen \\ Naval Health Research Center, cynthia.thomsen@med.navy.mil \\ Valerie A. Stander \\ Naval Health Research Center, stander@med.navy.mil \\ Stephanie K. McWhorter \\ Naval Health Research Center, stephanie.mcwhorter@med.navy.mil \\ Mandy M. Rabenhorst \\ Northern Illinois University, mrabenho@niu.edu \\ Joel S. Milner \\ Northern Illinois University, jmilner@niu.edu
}

Follow this and additional works at: https://digitalcommons.unl.edu/usnavyresearch

Thomsen, Cynthia J.; Stander, Valerie A.; McWhorter, Stephanie K.; Rabenhorst, Mandy M.; and Milner, Joel S., "Effects of combat deployment on risky and self-destructive behavior among active duty military personnel" (2011). U.S. Navy Research. 47.

https://digitalcommons.unl.edu/usnavyresearch/47

This Article is brought to you for free and open access by the U.S. Department of Defense at DigitalCommons@University of Nebraska - Lincoln. It has been accepted for inclusion in U.S. Navy Research by an authorized administrator of DigitalCommons@University of Nebraska - Lincoln. 


\title{
Effects of combat deployment on risky and self-destructive behavior among active duty military personnel
}

\author{
Cynthia J. Thomsen ${ }^{\mathrm{a},{ }^{*}}$, Valerie A. Stander ${ }^{\mathrm{a}}$, Stephanie K. McWhorter ${ }^{\mathrm{a}}$, Mandy M. Rabenhorst ${ }^{\mathrm{b}}$, \\ Joel S. Milner ${ }^{\mathrm{b}}$ \\ a Behavioral Science and Epidemiology, Naval Health Research Center, 140 Sylvester Road, San Diego, CA 92106-3521, USA \\ ${ }^{\mathrm{b}}$ Center for the Study of Family Violence and Sexual Assault, Northern Illinois University, 125 Presidents Blvd, DeKalb, IL 60640, USA
}

\section{A R T I C L E I N F O}

Article history:

Received 29 September 2010

Received in revised form

25 February 2011

Accepted 7 April 2011

\section{Keywords:}

Combat deployment

Self-harm

Suicide attempts

Illegal drugs

Risk-taking

Unprotected sex

Depression

Anxiety

PTSD

\begin{abstract}
A B S T R A C T
Although research has documented negative effects of combat deployment on mental health, few studies have examined whether deployment increases risky or self-destructive behavior. The present study addressed this issue. In addition, we examined whether deployment effects on risky behavior varied depending on history of pre-deployment risky behavior, and assessed whether psychiatric conditions mediated effects of deployment on risky behavior. In an anonymous survey, active duty members of the U.S. Marine Corps and U.S. Navy $(N=2116)$ described their deployment experiences and their participation in risky recreational activities, unprotected sex, illegal drug use, self-injurious behavior, and suicide attempts during three time frames (civilian, military pre-deployment, and military postdeployment). Respondents also reported whether they had problems with depression, anxiety, or PTSD during the same three time frames. Results revealed that risky behavior was much more common in civilian than in military life, with personnel who had not deployed, compared to those who had deployed, reporting more risky behavior and more psychiatric problems as civilians. For the current time period, in contrast, personnel who had deployed (versus never deployed) were significantly more likely to report both risky behavior and psychiatric problems. Importantly, deployment was associated with increases in risky behavior only for personnel with a pre-deployment history of engaging in risky behavior. Although psychiatric conditions were associated with higher levels of risky behavior, psychiatric problems did not mediate associations between deployment and risky behavior. Implications for understanding effects of combat deployment on active duty personnel and directions for future research are discussed.
\end{abstract}

Published by Elsevier Ltd.

\section{Introduction}

High levels of continuing U.S. military deployments in support of war efforts in Iraq and Afghanistan have heightened concerns about effects of combat on military personnel. Research has documented increases in psychological problems among personnel returning from combat deployment. Although most studies have focused on post-traumatic stress disorder (PTSD), increases in related problems such as depression and substance abuse also have been demonstrated (Boscarino, 1995; Hoge et al., 2004). Comparatively less attention has been paid to potential effects of deployment on other psychological and behavioral health issues. The present study investigated the effects of combat deployment on

\footnotetext{
* Corresponding author. Tel.: +1 619553 7174; fax: +1 6195538459 .

E-mail address: cynthia.thomsen@med.navy.mil (C.J. Thomsen).
}

a constellation of behaviors that are either overtly self-destructive or that place the individual at substantial risk of harm.

"Risky or self-destructive" behavior is a broad category. At one end of the spectrum are activities that could result in harm to the self but are not necessarily intended to do so, such as risky recreation (e.g., extreme sports), risky driving (e.g., driving without a seatbelt or after drinking), risky sexual activities (e.g., sex with strangers, unprotected sex), and substance use or abuse; at the other end of the continuum are behaviors explicitly intended to harm the self, including deliberate self-harm without suicidal intent ("self-harm"), suicide attempts, and suicide. Although these behaviors may be subsumed under the rubric of "self-injurious thoughts and behaviors" (Silverman et al., 2007), they do not constitute a homogenous set; the behaviors likely differ in several respects, including their prevalence, motivational underpinnings, the potential severity of adverse consequences, and the nature and magnitude of barriers to performing them. Nonetheless, different 
types of risky behaviors tend to co-occur. For example, individuals who engage in self-harm are more likely than those who do not to attempt suicide (e.g., Muehlenkamp and Gutierrez, 2007), use illicit drugs (e.g., Matsumoto et al., 2005), and be involved in other risky behaviors (e.g., Laye-Gindhu and Schonert-Reichl, 2005). Similarly, both heavy drinking and heavy smoking are associated with risky sexual behavior (e.g., Leigh et al., 1994) and risky driving (e.g., Fear et al., 2008). Moreover, different types of risky behavior often share common predictors. For example, most types of risky behavior are more common among young men than among women or older men (Nell, 2002; Zuckerman, 2007).

The present study examined effects of combat deployment on five specific types of risky or self-destructive behavior: dangerous recreational activities, unprotected sex with someone other than a regular partner, illegal drug use, self-harm, and suicide attempts. Our primary hypothesis was that rates of each risky behavior would be higher following combat deployment than before deployment. Of the five types of risky or self-destructive behavior considered in the present study, only substance use and suicide-related thoughts and behaviors have received significant research attention as possible consequences of military deployment. Combat deployment has been associated with increased likelihood of drug and alcohol problems (Browne et al., 2008; Calhoun et al., 2008; Hoge et al., 2004; Koenen et al., 2003). However, empirical findings regarding the association between deployment and suicide-related ideations and behaviors have been weak and inconsistent (Centers for Disease Control, 1987; Hall, 1996; Hansen-Schwartz et al., 2002; Kaplan et al., 2009; O'Toole and Cantor, 1995; Thoresen et al., 2003; Wojcik et al., 2009; Wong et al., 2001).

Although we are aware of no previous research examining the impact of deployment on risky recreational activity, unprotected sex, or self-harm, combat deployment has been linked with increases in risky driving behaviors (e.g., speeding, failing to wear one's seat belt; Fear et al., 2008). In addition, in a sample of Army soldiers returning from Iraq, specific combat experiences were related to scores on a scale assessing general preferences for engaging in risky activities (e.g., seeking the "thrill of danger," liking to drive fast; Killgore et al., 2008). However, because risk-taking preferences prior to deployment were not assessed in this study, it is not possible to determine whether combat exposure changed risk preferences, or whether those who preferred risky situations sought out combat exposure; indeed, some evidence suggests that military personnel with higher risk-taking proclivities may be more likely to deploy and to volunteer for hazardous duties (Bell et al., 2010; Bricknell et al., 1999; Jobe et al., 1983; Zuckerman, 2007).

There are several mechanisms by which combat deployment might increase risky behavior. Joiner's (2005) interpersonalpsychological theory of suicidal behavior posits that repeated exposure to pain or fear-inducing situations (e.g., through combat exposure) results in habituation, i.e., greater tolerance for pain and lower levels of fear. In turn, this habituation increases the individual's capability to enact lethal self-injury. Using similar logic, Killgore et al. (2008) suggested that habituation to danger as a result of long-term combat exposure may increase risk-taking propensities among veterans. In support of these formulations, recent evidence indicates that combat exposure is associated with self-reported habituation to pain and decreases in fear (Brenner et al., 2008; Bryan et al., 2010). A related possibility is that returning combat veterans may engage in risky behavior in an attempt to create an "adrenaline rush" similar to those that they experienced in combat (Vaughan, 2006).

Increases in risky behaviors following deployment also may result from deployment-related increases in psychiatric symptoms such as depression and PTSD (e.g., Hoge et al., 2004). Although negative emotional states have been linked with both suicidality and self-harm (e.g., Whitlock and Knox, 2007), links with less overtly self-destructive behaviors such as risky recreation, unprotected sex, and illegal drug use are less clear. Nonetheless, risky behaviors that are not intrinsically self-destructive sometimes may be undertaken, either consciously or subconsciously, with selfdestructive intent. Consistent with this view, accidental deaths and suicides have been found to have common risk factors (Stea et al., 2002; Thoresen and Mehlum, 2004). Previous findings of elevated rates of accidental death among combat veterans (Catlin Boehmer et al., 2004; Kang et al., 2002; Knapik et al., 2009) may thus reflect some instances in which individuals purposefully engaged in risky behaviors for self-destructive purposes. In the present study, we examined whether psychiatric conditions (depression, anxiety, and PTSD) were associated with risky behavior. In addition, we examined whether these conditions mediate the impact of deployment on risky behaviors.

In addition to predicting that combat deployment would increase rates of risky behavior in general, we expected deployment effects to differ depending on the individual's prior history of risky behavior. Specifically, effects of deployment in increasing risky behavior were expected to be most pronounced among those who had engaged in the behavior previously. Prior engagement in risky behavior may be a marker for psychological difficulties or vulnerabilities that place the individual at risk of developing adverse reactions to deployment. At a minimum, prior engagement in a behavior indicates that it is part of the individual's behavioral repertoire. If the individual has engaged in a behavior in the past, perhaps as a means of coping with distress (e.g., Klonsky, 2007), he or she may turn to the same strategy again to cope with the stresses associated with deployment or with readjustment following deployment. We could locate no prior research investigating whether deployment effects are moderated by prior behaviors.

In the present study, we first used within-subjects analyses to examine changes in risky behavior from civilian to military life (for both combat deployed and non-deployed personnel) and from predeployment to post-deployment life (for combat deployed personnel only). Next, we directly compared rates of risky behavior among active duty personnel who had previously combat deployed and those who had not. In addition, we examined whether effects of combat deployment on risky behavior differed depending on whether the individual had engaged in that behavior in the past. We predicted that effects of deployment on a given risky behavior would be stronger among individuals who had a history of engaging in that type of behavior. Each analysis was conducted across five different types of risky behavior (risky recreational activities, unprotected sex, illegal drug use, self-harm, and suicide attempts), allowing for a determination of whether combat deployment had similar or distinct effects on different types of behavior. A final set of analyses examined patterns of psychiatric problems (depression, anxiety, and PTSD) before and after deployment and among deployers and non-deployers, and tested whether deployment-related increases in psychiatric problems might account for any effects of deployment on risky or selfdestructive behaviors.

\section{Methods}

\subsection{Participants}

The Naval Health Research Center (NHRC) Combat Stress and Substance Use survey was conducted between August 2006 and August 2007. Participants were active duty military personnel serving at U.S. Marine Corps (USMC) installations in Southern California and Arizona within three major commands: Marine Corps Air Station Yuma Arizona (primarily 3rd Marine Air Wing); 
1st Marine Logistics Group, Camp Pendleton, California; and 1st Marine Division, Camp Pendleton and 29 Palms, California. These commands represent air, support, and infantry units. A total of 2612 personnel attended survey recruiting sessions. Of these, 2539 participants completed some part of the survey, yielding a $97 \%$ participation rate. The present sample included only participants who provided data about their deployments and who completed at least 7 of the 8 items assessing risky behavior $(N=2116$; response rate $=81 \%$ ). Most participants $(93 \%)$ were in the USMC; the other $7 \%$ were Navy (USN) personnel embedded within USMC units. As expected, the majority of participants were young $(M=24.09 \mathrm{yrs}$, $S D=5.30$ ), male (92\%), and junior-ranking enlisted personnel (E1 - E5 = 85\%); only 4\% were commissioned officers. Forty-seven percent reported at least some college or other post-secondary technical training. Approximately equal numbers were single (47\%) and married or cohabiting (46\%), with the remaining $7 \%$ being divorced, separated, or widowed. Compared to members of the USMC as a whole (Marine Corps Community Services, 2007), USMC participants in the present sample were significantly younger (76\% sample vs. $67 \%$ USMC aged 25 or younger), lower in rank (44\% sample vs. 39\% USMC ranked lower than E4), less likely to be officers (4\% sample vs. $11 \%$ USMC), and more likely to be female ( $8 \%$ sample vs. $6 \%$ USMC), $p s<0.01$. USMC personnel in the sample did not differ from the general USMC in terms of marital status (44\% of sample and $45 \%$ of USMC married).

\subsection{Survey procedures}

This research was conducted in compliance with all federal regulations regarding the protection of human subjects in research, and was approved by an Institutional Review Board at NHRC (protocol \#NRHC 2006.0008). Commanders referred personnel from participating units to meet with civilian survey administrators at prearranged times and locations, based on their availability within the training schedule. Groups ranged in size from 28 to 408 . At the beginning of each session, the survey was introduced as an anonymous questionnaire concerning the relationship between combat stress and substance use. Informed consent information was read aloud. Consent information included the following: participation was voluntary, with no repercussion for nonparticipation; participants could leave blank any questions they did not want to answer, and could quit at any time; surveys were completely anonymous and would be processed by civilian researchers, not military personnel; and individual data would never be presented. To better ensure that participation was voluntary, officers and enlisted personnel participated in separate locations. To increase the sense of anonymity, participants sealed their own completed surveys in stamped envelopes addressed to Northern Illinois University (NIU); envelopes were mailed immediately following the session. Personnel who chose not to participate were asked to sit quietly and then seal their blank surveys in their mailing envelopes as though they had participated.

The survey assessed demographic characteristics (sex, age, rank, education level, marital status, number of children) and combat deployment history (e.g., dates, locations, duties). A combat deployment was defined by the receipt of imminent danger pay or combat zone tax exclusion benefits; non-combat deployments were not considered. Eight items assessed risky behavior. Respondents were asked to indicate whether they had engaged in five different types of behavior: risky recreational activities ("done things for fun that were so dangerous you were likely to be injured or killed"), unprotected sex with someone other than one's regular partner, illegal drug use, self-harm ("hurt yourself physically to calm down or feel better when you were tense, anxious, or upset"), and attempted suicide. Self-harm and illegal drug use were each assessed by a single item; the other types of behavior were each assessed by two items: one asked about engaging in the behavior while drinking, and the other asked about engaging in the behavior while not drinking (e.g., "attempted suicide after drinking alcohol"; "attempted suicide when you were not drinking alcohol"). In each case, respondents reported whether they had engaged in the behavior (a) as a civilian, (b) while in the military before their first combat deployment, and (c) after returning from their first combat deployment. Finally, for each of the same three time frames, respondents were asked whether they had ever "been told by a doctor or mental health counselor" that they had (1) depression, (2) anxiety, or (3) PTSD.

\subsection{Analytic strategy}

Prior to testing our hypotheses regarding the effects of deployment on risky behavior, we provide descriptive information about both combat deployments and rates of each type of risky behavior within our sample. This includes an examination of demographic factors associated with both deployment and risky behavior, as well as associations between different types of risky behavior. We next investigated changes in overall rates of risky behavior from civilian to military/pre-deployment life, separately for deployers and nondeployers. The hypothesis that risky behavior would increase following deployment was examined in two ways. First, we examined changes in risky behavior from pre-deployment to postdeployment among personnel who had combat deployed. Second, we compared the risky behavior of deployers and non-deployers during different time periods (as a civilian, while in the military/ pre-deployment, and currently). For deployers, current behavior was defined as post-deployment behavior; for non-deployed personnel, current behavior was defined as pre-deployment behavior (as there was no deployment period). In this set of analyses, deployment effects on risky behavior are indicated by differences between deployers and non-deployers in current behavior (that were not apparent prior to deployment). After examining the overall impact of deployment on risky behavior, additional analyses were conducted to determine whether the impact of deployment on each specific type of risky behavior was moderated by prior engagement in that type of risky behavior. A final set of analyses examined whether deployment effects on risky behavior were mediated by mental health issues.

\section{Results}

\subsection{Combat deployment}

More than half $(58 \% ; n=1225)$ of respondents in the present sample had been combat deployed. Most deployers (57\%) had one deployment, $29 \%$ had two, and $14 \%$ had three or more. Among combat deployers, 97\% had deployed in support of Operation Iraqi Freedom or Operation Enduring Freedom (91\% OIF, 19\% OEF, 13\% other operations [e.g., Desert Shield/Storm]). The modal deployment length was 7 months, with $35 \%$ of deployments being shorter and $19 \%$ being longer ( $M=6.86 ; M d n=7$; range: $1-19$ months). Threequarters of deployers had returned from deployment within the past year (45\% in the past 6 months). Men (58\%) and women (53\%) were equally likely to have deployed, $\chi^{2}(1, N=2066)=2.09$, n.s. However, personnel who were married or cohabiting (69\%) or divorced, separated, or widowed (80\%) were more likely to have deployed than those who were single $(45 \%), \chi^{2}(2, N=1921)=130.38$, $p<0.001$. USN personnel (70\%) were more likely to have been deployed than USMC personnel (57\%), $\chi^{2}(1, N=2058)=9.93$, $p<0.01$. In addition, deployers, compared to non-deployers, were significantly older $(M s=25.67$ vs. 21.90 years), higher in rank 
Table 1

Associations (crude odds ratios) between lifetime engagement in high-risk behaviors and demographic characteristics.

\begin{tabular}{llllll}
\hline Predictor & \multicolumn{3}{l}{ Type of high-risk behavior } \\
\cline { 2 - 6 } & $\begin{array}{l}\text { Risky } \\
\text { recreation }\end{array}$ & $\begin{array}{l}\text { Unprotected } \\
\text { sex }\end{array}$ & $\begin{array}{l}\text { Illegal } \\
\text { drug use }\end{array}$ & Self-harm & $\begin{array}{l}\text { Suicide } \\
\text { attempt }\end{array}$ \\
\hline Unprotected sex & $5.42^{* * *}$ & & & & \\
Illegal drug use & $3.45^{* * *}$ & $3.54^{* * *}$ & & & \\
Self-harm & $6.16^{* * *}$ & $2.39^{* * *}$ & $2.08^{* * *}$ & & \\
Suicide attempt & $4.43^{* * *}$ & $3.42^{* * *}$ & $2.43^{* * *}$ & $11.84^{* * *}$ & \\
Male & $2.91^{* * *}$ & $1.42^{*}$ & $1.70^{* *}$ & 1.02 & $0.59^{*}$ \\
Older age & $0.93^{* * *}$ & 0.99 & $0.94^{* * *}$ & $0.91^{* * *}$ & $0.95^{*}$ \\
Higher rank & $0.81^{* * *}$ & 0.99 & $0.78^{* * *}$ & $0.77^{* * *}$ & $0.75^{* * *}$ \\
Higher education & $0.82^{* * *}$ & 1.07 & $0.82^{* *}$ & $0.75^{* * *}$ & 0.82 \\
USN (vs. USMC) & $0.40^{* * *}$ & $0.59^{* *}$ & $0.50^{* * *}$ & $0.56^{*}$ & 0.71 \\
Single & $1.57^{* * *}$ & $1.26^{*}$ & 1.15 & $1.42^{* *}$ & 1.19 \\
Div/sep/widowed $^{\mathrm{a}}$ & 1.13 & $1.91^{* *}$ & 1.09 & 1.02 & $2.35^{* *}$ \\
\hline
\end{tabular}

USN = Navy; USMC = Marine Corps. Ns vary from 1901 to 2097. ORs greater than 1.0 indicate risk factors and ORs less than 1.0 indicate protective factors for high-risk behavior.

${ }^{*} p<0.05 .{ }^{* *} p<0.01 .{ }^{* * *} p<0.001$

a The reference group was married/cohabiting.

$(\mathrm{Ms}=4.62$ [E4-E5] vs. 3.24 [E3]), and higher in education $(\mathrm{Ms}=2.57$ vs. 2.44 , where 2 = high school diploma and 3 =some college), $t$ s $(1974.8-2031.1) \geq 4.3$, ps $<0.001$.

\subsection{Risky behavior}

Nearly three-quarters (73\%) of participants reported engaging in one or more types of risky behavior in their lifetimes (i.e., as a civilian or while in the military). Half (52\%) reported engaging in unprotected sex with someone other than a regular partner, and half (49\%) had engaged in recreational activities dangerous enough to cause serious injury or death. Two in five (41\%) had used illegal drugs, and one in five (19\%) reported engaging in self-harm. Attempted suicide was reported by $7 \%$ of respondents. Comparisons of lifetime rates of risky behavior while drinking versus not drinking alcohol were conducted for the three types of behavior for which this was assessed. Respondents were more likely to report engaging in unprotected sex when they had been drinking than when they had not ( $48 \%$ vs. $45 \%)$, Cochran's $Q(1, N=2094)=13.95$, $p<0.001$. In contrast, respondents were more likely to report engaging in risky recreation or attempting suicide while not drinking than while drinking (for risky recreation, $44 \%$ vs. $35 \%$, Cochran's $Q(1, N=2098)=89.25, p<0.001$; for suicide attempts, $5 \%$ vs. $3 \%$, Cochran's $Q(1, N=2104)=15.14, p<0.001)$. Despite these differences, comparisons of deployers and non-deployers yielded identical patterns of effects for the alcohol and no-alcohol items; therefore, alcohol and no-alcohol items for a given type of risky behavior were combined into a single index for all subsequent analyses.

Table 1 provides associations among lifetime reports of different types of risky behavior. Respondents who had engaged in any one type of risky behavior were at significantly increased risk for engaging in every other type of risky behavior. As can be seen in Table 1, these associations were substantial, with odds ratios (ORs) ranging from 2 to nearly 12 . An exploratory principal components analysis with varimax rotation performed on lifetime rates of the five risky behaviors revealed two underlying factors with eigenvalues greater than 1 . The first factor, accounting for $39 \%$ of the total variance, consisted of unprotected sex, use of illegal drugs, and risky recreation; the second factor, accounting for $21 \%$ of the total variance, consisted of self-harm and suicide attempts. All loadings on the primary factor were greater than 0.7 , and no cross-loadings were greater than 0.3 . This suggests that the five risky behaviors constitute two underlying clusters, one representing deliberate self-harm and one representing behaviors that may increase the likelihood of self harm, but are not necessarily intended to do so.

Considering the demographic predictors of lifetime risky behavior, men were more likely than women to engage in risky, but not explicitly self-destructive, behaviors; women were significantly more likely to report attempting suicide (see Table 1). Relative to USMC personnel, USN personnel were significantly less likely to engage in all of the behaviors except for suicide attempts. Age, education, and military rank were unrelated to the likelihood of engaging in unprotected sex, but were negatively related to the other types of behavior. With respect to marital status, respondents who were single or formerly married (i.e., divorced, separated, or widowed) were generally more likely to engage in risky behaviors than were married or cohabiting respondents (see Table 1 ).

\subsection{Timing of risky behavior}

Fig. 1 depicts the mean number of different risky behaviors reported by deployed and non-deployed personnel for each of the three time frames (i.e., civilian, pre-deployment, and current). It is important to note that for non-deployed personnel, estimates of pre-deployment and current rates of risky behavior are based on the same data, because both time frames are equivalent for this group. In the sample as a whole, the likelihood of each type of risky behavior decreased significantly from the civilian period to the military/predeployment period, McNemar $\chi^{2}(1, N s=2054-2116) \geq 17.78$, ps $<0.001$. Although the decline was most pronounced for illegal drug use (from $39 \%$ to $5 \%$ ), it was substantial for the other behaviors as well: self-harm ( $13 \%$ to $6 \%$ ), suicide attempts (5\% to $2 \%$ ), risky recreation (38\% to $22 \%$ ), and unprotected sex (37\% to $29 \%$ ). Table 2 provides the percentage of respondents reporting each specific risky behavior during each time frame, separately for deployers and non-deployers. Declines in risky behavior from civilian to military/ pre-deployment life were generally greater for non-deployed than for deployed personnel. For non-deployed personnel, all forms of risky behavior decreased significantly from civilian to military/predeployment periods, McNemar $\chi^{2}(1, N s=874-891) \geq 15.56$, ps $<0.001$; among deployed personnel, the reduction in risky behavior was significant for four of the five behaviors $\left[\chi^{2}\right.$ $(1, N s=1180-1225) \geq 7.58, p s<0.01]$, but did not reach significance for suicide attempts $\left[\chi^{2}(1, N=1225)=2.94, p<0.10\right]$.

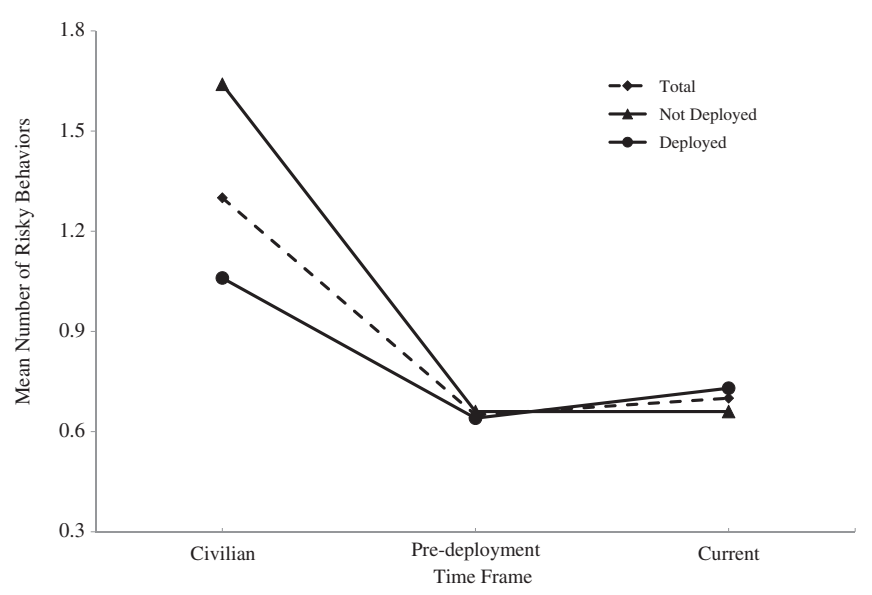

Fig. 1. Mean number of risky behaviors reported by time period. Note. For nondeployed personnel, pre-deployment and current time frames are equivalent and are represented by the same data point 
Table 2

Percentage of respondents reporting each type of high-risk behavior by time period and combat deployment status.

\begin{tabular}{lllll}
\hline Type of behavior/Deployment status & \multicolumn{2}{l}{ Time period } & \\
\cline { 2 - 4 } & Civilian & Pre-dep & Post-dep & Lifetime \\
\hline High-risk recreation & 38 & 22 & 25 & 49 \\
Deployed $(n=1225)$ & 30 & 22 & 25 & 44 \\
Non-deployed $(n=891)$ & 50 & 22 & - & 56 \\
Unprotected sex & 37 & 29 & 29 & 52 \\
Deployed $(n=1225)$ & 33 & 29 & 29 & 51 \\
Non-deployed $(n=891)$ & 42 & 28 & - & 54 \\
Illegal drug use & 39 & 5 & 7 & 41 \\
Deployed $(n=1180)$ & 33 & 6 & 7 & 36 \\
Non-deployed $(n=874)$ & 47 & 5 & - & 48 \\
Self-harm & 13 & 6 & 10 & 19 \\
Deployed $(n=1220)$ & 8 & 5 & 10 & 16 \\
Non-deployed $(n=889)$ & 19 & 8 & - & 23 \\
Suicide attempt & 5 & 2 & 2 & 7 \\
Deployed $(n=1225)$ & 3 & 2 & 2 & 6 \\
Non-deployed $(n=891)$ & 7 & 3 & - & 9
\end{tabular}

pre-dep = pre-deployment; post-dep = post-deployment.

The hypothesis that risky behavior would increase following deployment was examined in two ways. First, we examined changes in high-risk behavior from pre-deployment to postdeployment among personnel who had combat deployed. Relevant percentages are provided in Table 2 . Both risky recreation and self-harm increased significantly from pre- to post-deployment, McNemar $\chi^{2}(1, N s=1220-1225)=8.28$ and 31.51, respectively, ps $<0.01$. In contrast, changes in rates of unprotected sex, illegal drug use, and suicide attempts from pre- to post-deployment were not significant, McNemar $\chi^{2}(1, N s=1180$ to 1225$) \leq 2.54$, n.s.

As an additional way of examining deployment effects on risky behavior, we conducted a series of logistic regression analyses comparing the risky behavior of deployers and non-deployers during three different time frames: as a civilian; while in the military, pre-deployment; and currently. For deployers, current behavior was defined as post-deployment behavior; for nondeployed personnel, current behavior was defined as predeployment behavior (as there was no deployment period). In each analysis, demographic variables (sex, age, rank, education, service [USMC vs. USN], and marital status) were entered on the first step, followed by deployment status. Table 3 provides the adjusted odds ratios for deployment effects on each type of risky behavior during each time period. These ORs represent the extent to which deployers and non-deployers differed in the likelihood of

Table 3

Adjusted odds ratios (ORs) representing differences between deployed and nondeployed personnel in rates of high-risk behaviors.

\begin{tabular}{|c|c|c|c|c|c|c|}
\hline \multirow[t]{2}{*}{ Type of behavior } & \multicolumn{2}{|c|}{ Civilian } & \multicolumn{2}{|c|}{ Pre-deployment } & \multicolumn{2}{|c|}{ Current $^{\mathrm{a}}$} \\
\hline & OR & $\left(\mathrm{Cl}_{95 \%}\right)$ & OR & $\left(\mathrm{Cl}_{95 \%}\right)$ & OR & $\left(\mathrm{Cl}_{95 \%}\right)$ \\
\hline High-risk recreation & 0.56 & $0.45,0.70$ & 1.14 & $0.89,1.47$ & 1.59 & $1.24,2.04$ \\
\hline Unprotected sex & 0.68 & $0.55,0.85$ & 1.03 & $0.82,1.29$ & 1.15 & $0.91,1.46$ \\
\hline Illegal drug use & 0.72 & $0.58,0.90$ & 1.42 & $0.88,2.29$ & 1.86 & $1.18,2.95$ \\
\hline Self-harm & 0.62 & $0.45,0.85$ & 0.69 & $0.46,1.05$ & 1.52 & $1.06,2.20$ \\
\hline Suicide attempt & 0.66 & $0.39,1.12$ & 1.03 & $0.53,2.03$ & 0.86 & $0.44,1.68$ \\
\hline
\end{tabular}

ORs greater than 1.0 (less than 1.0) indicate greater (lower) likelihood of high-risk behavior among personnel who had combat deployed, relative to those who had not. Statistically significant ORs $(p<0.05)$ are in boldface type.

a Current behavior was defined as post-deployment behavior among personnel who had previously deployed, and as pre-deployment military behavior among personnel who had not previously deployed. risky behavior after controlling for demographic factors, with ORs greater than 1.0 indicating that risky behavior was more common among deployers.

As can be seen in the first column of Table 3, during the civilian time frame, non-deployers were more likely than deployers to report engaging in risky behavior. The difference between the two groups was significant for all types of risky behavior except suicide attempts. Risky behavior while in the military but prior to deployment revealed a very different pattern. There were no significant differences between deployers and non-deployers in the likelihood of any type of risky behavior for this time period (see the second column of Table 3). Most relevant to our primary hypothesis are the comparisons between deployers and non-deployers in current rates of risky behavior. As shown in the third column of Table 3, deployers were significantly more likely than nondeployers to report current engagement in risky recreation, illegal drug use, and self-harm; the two groups did not differ in reported rates of unprotected sex or suicide attempts.

\subsection{Previous risky behavior, combat deployment, and current risky behavior}

The next set of analyses examined whether the impact of deployment on each specific type of risky behavior was moderated by prior engagement in that type of risky behavior. To examine this issue, we conducted logistic regression analyses in which current risky behavior was predicted from demographic factors (entered on the first step), prior engagement in the behavior in question (entered on the second step), deployment status (entered on the third step), and the interaction between prior behavior and deployment status (entered on the fourth step). For those who had not deployed, previous behavior was defined as civilian behavior; for those who had deployed, it included both civilian behavior and military behavior prior to deployment. Results of these analyses are provided in Table 4. Among the demographic variables, only being divorced, separated, or widowed emerged as a consistent predictor of all forms of risky behavior. Not surprisingly, the strongest predictor of current engagement in each specific type of risky behavior was having engaged in that type of behavior previously. Nonetheless, controlling for previous behavior did not alter the pattern of

Table 4

Results of logistic regression analyses predicting current high-risk behaviors (adjusted odds ratios).

\begin{tabular}{llllll}
\hline \multirow{2}{*}{ Predictor } & \multicolumn{4}{l}{ Type of high-risk behavior } \\
\cline { 2 - 6 } & $\begin{array}{l}\text { Risky } \\
\text { recreation }\end{array}$ & $\begin{array}{l}\text { Unprotected } \\
\text { sex }\end{array}$ & $\begin{array}{l}\text { Drug } \\
\text { use }\end{array}$ & Self-harm & $\begin{array}{l}\text { Suicide } \\
\text { attempt }\end{array}$ \\
\hline Male & $3.12^{* * *}$ & 1.07 & 2.27 & 1.05 & 0.58 \\
Older age & $0.95^{* *}$ & $0.96^{* *}$ & 0.95 & $0.94^{*}$ & 0.97 \\
Higher rank & 0.99 & 1.08 & 0.83 & 1.01 & 0.76 \\
Higher education & 1.18 & 1.06 & $1.52^{*}$ & 0.96 & 1.23 \\
USN (vs. USMC) & $0.48^{* *}$ & $0.62^{*}$ & 1.28 & 0.84 & 0.79 \\
Single & 1.16 & $1.58^{* * *}$ & 1.14 & 1.02 & 0.78 \\
Div/sep/widowed & $2.52^{* *}$ & $2.55^{* * *}$ & $2.59^{* *}$ & $1.86^{*}$ & $3.90^{* *}$ \\
Prior behavior & $4.65^{* * *}$ & $3.29^{* * *}$ & $5.49^{* * *}$ & $7.94^{* * *}$ & $8.58^{* * *}$ \\
Combat deployment & $1.94^{* * *}$ & 1.19 & $2.14^{* *}$ & $1.92^{* *}$ & 0.86 \\
Prior behavior $\times$ & $2.54^{* * *}$ & 1.27 & 1.39 & $2.27^{*}$ & 1.68 \\
\multicolumn{1}{c}{ deployment } & & & & &
\end{tabular}

ORs greater than 1.0 indicate risk factors and ORs less than 1.0 indicate protective factors for high-risk behavior. Demographic variables were entered on Step 1, prior high-risk behavior (of the same type as the behavior being predicted) on Step 2, combat deployment on Step 3, and the interaction on Step 4 of the analyses. ORs are reported for the step on which the predictor entered the model. USN = Navy; USMC $=$ Marine Corps.

${ }^{*} p<0.05 .{ }^{* *} p<0.01$. ${ }^{* *} p<0.001$.

a The reference group was married/cohabiting. 
differences between deployers and non-deployers in current risky behavior; as in the previous analyses (see Table 3), deployment was associated with increased rates of risky recreational activity, illegal drug use, and self-harm, but was unrelated to rates of unprotected sex and attempted suicide.

Of primary interest are the interactions of deployment and prior behavior in predicting high-risk behavior. Percentages of deployers and non-deployers reporting each type of risky behavior as a function of previous behavior are provided in Fig. 2. Statistically significant interaction effects were obtained for both risky recreational behavior and self-harm (see Table 4). Deployment was associated with increased likelihood of risky recreational behavior among respondents with a prior history of risky recreational behavior $\left(\mathrm{OR}=2.55, \mathrm{Cl}_{95 \%}: 1.82,3.58\right)$, but not among those with no such history ( $\mathrm{OR}=1.19, \mathrm{Cl}_{95 \%}$ : 0.77, 1.82). Similarly, deployment was associated with increased self-harm among those who had previously engaged in self-harm ( $\left.\mathrm{OR}=2.61, \mathrm{Cl}_{95 \%}: 1.35,5.05\right)$, but not among those with no history of self-harm (OR $=1.46, \mathrm{Cl}_{95 \%}: 0.89$, 2.40). The interaction was not statistically significant for unprotected sex, illegal drug use, or suicide attempts. Nonetheless, both unprotected sex and drug use showed a similar pattern of effects. That is, among personnel with no history of engaging in unprotected sex or using illegal drugs, current rates of that behavior did not significantly differ between deployers and non-deployers (for unprotected sex, $\mathrm{OR}=0.91, \mathrm{Cl}_{95 \%}$ : 0.64, 1.30; for drug use, $\mathrm{OR}=1.74$, $\mathrm{Cl}_{95 \%}$ : $\left.0.66,4.56\right)$. In contrast, among personnel with a prior history of engaging in the risky behavior, deployers displayed significantly higher current rates of the behavior than non-deployers (for unprotected sex, $\mathrm{OR}=1.49, \mathrm{Cl}_{95 \%}$ : 1.07, 2.08; for drug use, $\mathrm{OR}=2.29$, $\left.\mathrm{Cl}_{95 \%}: 1.34,3.90\right)$. Finally, for suicide attempts, there was no difference between deployers and non-deployers in current likelihood of behavior regardless of whether the individual reported a previous suicide attempt $\left(\mathrm{OR}=1.60, \mathrm{Cl}_{95 \%}: 0.45,5.68\right)$ or not $(\mathrm{OR}=0.65$, $\left.\mathrm{Cl}_{95 \%}: 0.29,1.49\right)$.

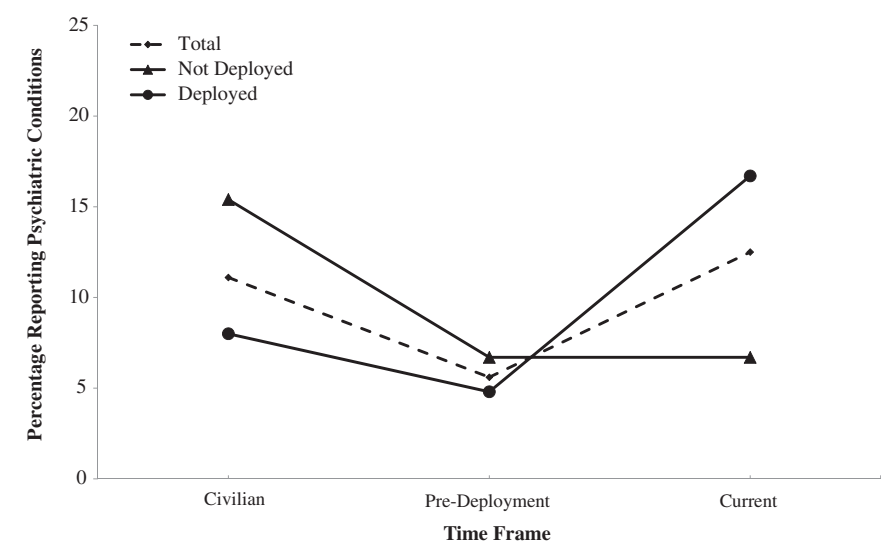

Fig. 3. Percentage of respondents reporting psychiatric conditions by time period. Note. For non-deployed personnel, pre-deployment and current time frames are equivalent and are represented by the same data point.

\subsection{Combat deployment and psychiatric problems}

Overall, $23 \%$ of respondents reported at least one psychiatric problem at some point in their lives, and those who had deployed (25\%) were significantly more likely than those who had not (20\%) to report a lifetime psychiatric problem, $\chi^{2}(1, N=2109)=5.70$, $p<0.05, \Phi=0.05$. Fig. 3 depicts the percentage of deployed and non-deployed respondents reporting psychiatric problems during each of the three time frames (i.e., civilian, pre-deployment, and current). As before, for non-deployed personnel, estimates of predeployment and current rates of risky behavior are based on the same data, because both time frames are equivalent for this group. As was the case for risky behaviors (see Fig. 1), Fig. 3 reveals a crossover interaction; although non-deployers initially were more likely

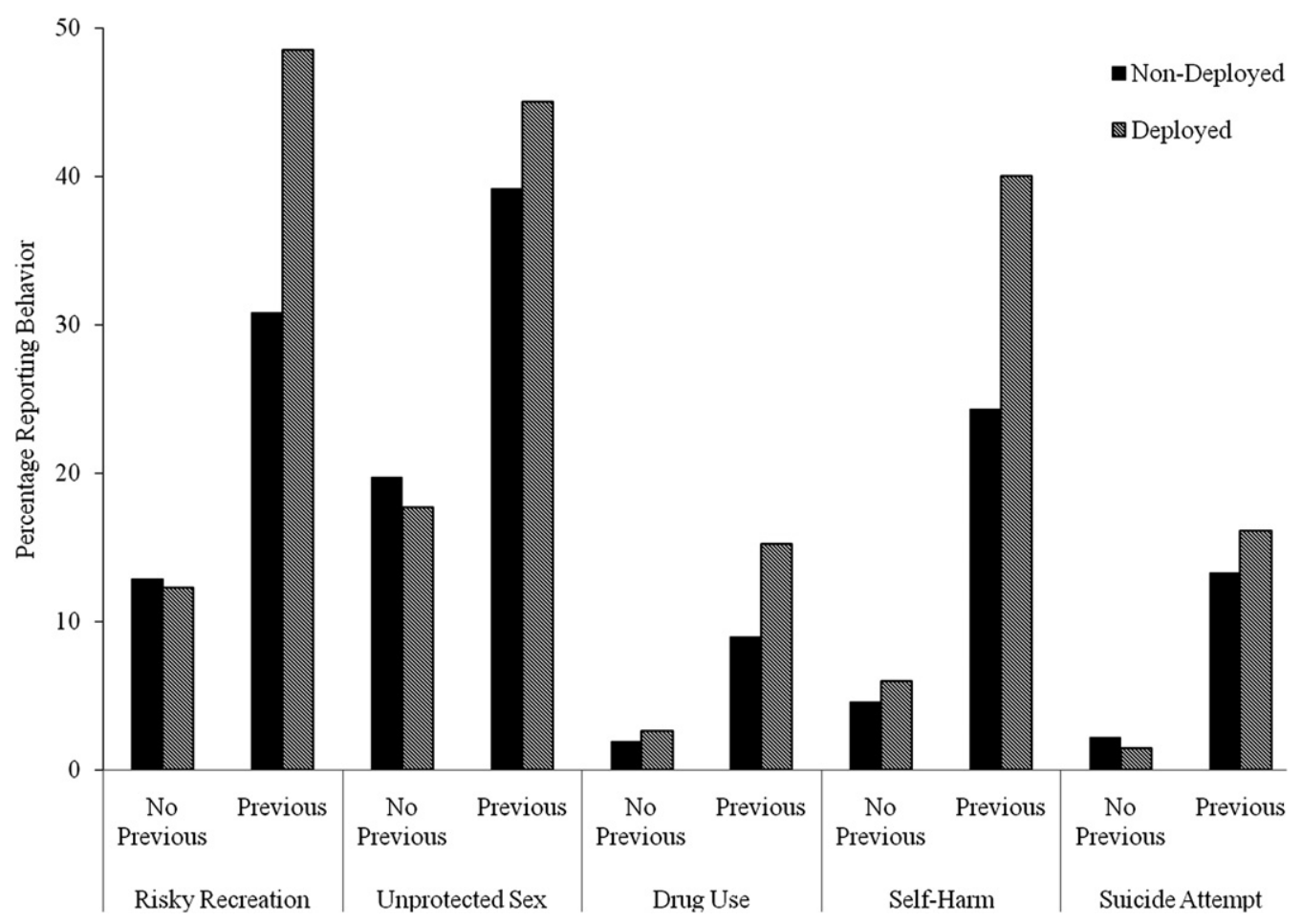

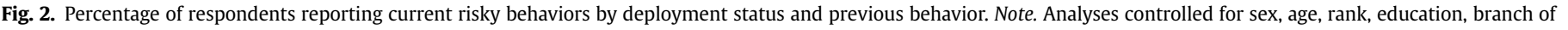
service, and marital status. 
Table 5

Percentage of respondents reporting each psychiatric condition by time period and combat deployment status.

\begin{tabular}{lccccc}
\hline \multirow{2}{*}{ Psychiatric condition/Deployment status } & \multicolumn{3}{l}{ Time period } & \\
\cline { 2 - 4 } \cline { 2 - 4 } & \multicolumn{2}{l}{ Civilian } & Pre-dep & Post-dep & Lifetime \\
\hline Depression & 9 & 5 & 10 & 18 \\
Deployed & 6 & 4 & 10 & 17 \\
Non-deployed & 14 & 6 & - & 18 \\
Anxiety & 6 & 4 & 9 & 14 \\
Deployed & 4 & 3 & 9 & 14 \\
Non-deployed & 8 & 5 & - & 13 \\
PTSD & 1 & 1 & 10 & 7 \\
Deployed & $<1$ & 1 & 10 & 11 \\
Non-deployed & 1 & 1 & - & 2 \\
\hline
\end{tabular}

pre-dep = pre-deployment; post-dep = post-deployment. PTSD = post-traumatic stress disorder. For deployed, $n=1225$; for non-deployed, $n=891$.

than deployers to report psychiatric conditions, within the current time frame, deployers were more likely to report psychiatric conditions.

Table 5 provides the percentage of respondents reporting each psychiatric condition during each time frame, separately for deployed and non-deployed personnel. Overall, depression was the most commonly reported problem (17\%), followed by anxiety (14\%), and PTSD (7\%). Deployers and non-deployers did not differ in lifetime rates of depression ( $17 \%$ and $18 \%$, respectively), or anxiety $(12 \%$ and $14 \%$, respectively), $p s \geq 0.20$. However, deployers were significantly more likely than non-deployers to report PTSD (11\% vs. $2 \%$ ), $\chi^{2}(1, N=2089)=62.28, p<0.001, \Phi=0.17$.

The next set of analyses examined differences in psychiatric problems between deployers and non-deployers during each time frame. As civilians, all three mental health conditions were more common among non-deployers than among deployers, $8.30 \leq \chi^{2}(1$, $N=2116) \leq 34.13, p<0.01,0.06 \leq \Phi \leq 0.12$. Differences between deployers and non-deployers during military service but before deployment were similar to civilian differences, but smaller in magnitude. Within this time frame, non-deployers were significantly more likely than deployers to report anxiety $(p<0.01)$, and the difference in depression approached significance $(p=0.05)$. However, rates of PTSD did not significantly differ $(p>0.4$; see Table 5). The pattern of differences between deployers and nondeployers during the current time frame was a complete reversal of the pattern observed during civilian life (and, to a lesser degree, military/pre-deployment life); that is, deployers reported significantly higher rates of all three conditions than non-deployers during the current period, $14.70 \leq \chi^{2}(1, N=2116) \leq 78.23$, $p<0.01,0.08 \leq \Phi \leq 0.19$ (see Table 5).

McNemar change tests were used to examine whether deployers were more likely to report each condition following deployment than before deployment (i.e., civilian and military/
Table 6

Correlations (Phi coefficients) between psychiatric conditions and risky behaviors.

\begin{tabular}{llll}
\hline Risky behavior & \multicolumn{2}{l}{ Condition } & \\
\cline { 2 - 4 } & Depression & Anxiety & PTSD \\
\hline Risky recreation & $0.17^{* * *}$ & $0.16^{* * *}$ & $0.10^{* * *}$ \\
Unprotected sex & $0.14^{* * *}$ & $0.14^{* * *}$ & $0.08^{* * *}$ \\
Drug use & $0.15^{* * *}$ & $0.09^{* * *}$ & 0.02 \\
Self-harm & $0.30^{* * *}$ & $0.26^{* * *}$ & $0.09^{* * *}$ \\
Suicide attempt & $0.36^{* * *}$ & $0.32^{* * *}$ & $0.14^{* * *}$ \\
\hline
\end{tabular}

Correlations are between lifetime reports of each diagnosis and of each type of risky behavior. PTSD = post-traumatic stress disorder.

${ }^{* * *} p<0.001$.

pre-deployment combined). Results revealed significant increases in the likelihood of both depression (McNemar $\chi^{2}[1$, $N=2116]=8.97, p<0.01$ ) and PTSD (McNemar $\chi^{2}[1$, $N=2116]=68.97, p<0.001)$. However, deployers were no more likely to report anxiety problems post- than pre-deployment, McNemar $\chi^{2}<1$, n.s.

\subsection{Do psychiatric problems mediate associations between deployment and risky behavior?}

The finding that psychiatric conditions show similar patterns of effects as risky behavior (as a joint function of deployment status and time frame) is consistent with the possibility that mental health problems mediate the association between deployment and risky behavior. Also consistent with this possibility, psychiatric problems were significantly correlated with risky behaviors (see Table 6). Not surprisingly, correlations of psychiatric conditions with overtly self-destructive behaviors (i.e., self-harm and suicide attempts) were generally stronger than correlations with risky behaviors that are not overtly self-destructive.

To directly examine the hypothesis that psychiatric problems mediate the association between deployment and risky behavior, we conducted additional logistic regression analyses paralleling those described in Section 3.4, each predicting a different specific type of current risky or self-destructive behavior. As before, to control for possible demographic differences between groups, demographics were entered on the first step. On the second step, we entered prior engagement in that type of risky behavior, as well as psychiatric condition (one variable representing prior psychiatric problems and one representing current problems). On the third and fourth steps, we entered deployment and the interaction of deployment $\times$ prior behavior, respectively. To the extent that psychiatric problems mediate the effects of deployment on risky behavior, we would expect effects of deployment on risky behavior to be weaker when history of psychiatric conditions is controlled than when it is not.

Table 7

Results of logistic regression analyses predicting current high-risk behaviors (adjusted odds ratios).

\begin{tabular}{|c|c|c|c|c|c|}
\hline \multirow[t]{2}{*}{ Predictor $^{\mathrm{a}}$} & \multicolumn{5}{|c|}{ Type of high-risk behavior } \\
\hline & $\begin{array}{l}\text { Risky } \\
\text { recreation }\end{array}$ & $\begin{array}{l}\text { Unprotected } \\
\text { sex }\end{array}$ & $\begin{array}{l}\text { Drug } \\
\text { use }\end{array}$ & Self-harm & $\begin{array}{l}\text { Suicide } \\
\text { attempt }\end{array}$ \\
\hline Prior behavior & $4.70^{* * *}$ & $3.17^{* * *}$ & $5.32^{* * *}$ & $7.19^{* * *}$ & $6.29^{* * *}$ \\
\hline Prior psychiatric condition & 1.16 & $1.39 *$ & 1.16 & 1.11 & 0.73 \\
\hline Current psychiatric condition & $4.79^{* * *}$ & $2.80^{* * *}$ & $2.48^{* * *}$ & $4.29^{* * *}$ & $14.00^{* * *}$ \\
\hline Combat deployment & $1.64^{* * *}$ & 1.06 & $1.90^{* *}$ & $1.52^{*}$ & 0.50 \\
\hline Prior behavior $\times$ deployment & $2.50^{* * *}$ & 1.18 & 1.33 & $2.09^{*}$ & 2.09 \\
\hline
\end{tabular}

${ }^{*} p<0.05 .{ }^{* *} p<0.01 .^{* * *} p<0.001$

a Demographic variables were entered on the first step and are not reported here (see Table 4); prior behavior and prior and current psychiatric condition were entered on

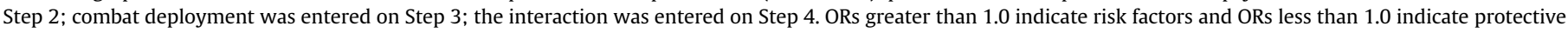
factors for high-risk behavior. ORs are reported for the step on which the predictor entered the model. USN $=$ Navy; USMC $=$ Marine Corps. 
Results of these analyses are provided in Table 7. Because they have been provided previously (see Table 4) and are unaltered in the present model, results for the demographic variables entered on the first step are not tabled. A comparison of Tables 4 and 7 with respect to the effects of prior behavior, combat deployment, and their interaction reveals that controlling for prior and current psychiatric conditions had little impact on the pattern of significant effects: (1) prior behavior remained a strong and significant predictor of every type of current behavior, even after controlling for psychiatric problems; (2) combat deployment remained a significant predictor of the same three outcomes as before (risky recreation, drug use, and self-harm); and (3) the interaction of prior behavior and deployment remained significant for the same two outcomes as before (risky recreation and self-harm). Thus, there was little evidence that psychiatric problems mediated deployment effects on risky behavior. Nonetheless, having a psychiatric condition during the current time frame was strongly associated with all five outcomes. In contrast, having a previous psychiatric condition was a significant predictor of only one current outcome (unprotected sex).

\section{Discussion}

The present study is the first, to our knowledge, to compare rates of a broad range of risky or self-destructive behaviors across deploying and non-deploying military personnel and, among deployers, before versus after deployment. More specifically, we examined the effects of deployment on rates of five types of risky or self-destructive behavior that seem quite disparate on the surface. Relationships between some of these behaviors have been demonstrated in the past (e.g., Muehlenkamp and Gutierrez, 2007; Zuckerman, 2007). However, we could locate no published research that has examined associations among such a broad constellation of risky behaviors. Although all five behaviors were significantly associated, factor-analytic results suggested that they constitute two distinct clusters, one representing deliberate self-harm (selfharm and suicide attempts), and the other representing risky behaviors that may or may not be motivated by self-destructive impulses (unprotected sex, risky recreational activities, and illegal drug use). Nonetheless, because each type of behavior is conceptually and practically distinct, we analyzed the effects of combat deployment on individual behaviors rather than on these two underlying factors.

In some cases, demographic correlates of different types of risky behavior were similar. For example, married personnel and those in the Navy (vs. Marine Corps) were generally at lower risk for engaging in all types of risky behavior. In other cases, associations with demographic factors varied across different types of risky behavior. For example, although higher ranking personnel, those who were older, and those with more education generally were less likely to report all types of risky behaviors, these characteristics were unrelated to the likelihood of unprotected sex. Patterns of sex differences also varied across the risky behaviors examined. Consistent with previous research, men were more likely than women to report risky activities associated with sensation seeking (risky recreational activities, unprotected sex, and illegal drug use; Zuckerman, 2007), but were less likely than women to report attempted suicide (Zhang et al., 2005). There was no sex difference in the likelihood of self-harm. Although some studies have reported that women are more likely than men to engage in self-harm (e.g., Whitlock et al., 2006), others (e.g., Briere and Gil, 1998), including a previous study of military recruits (Klonsky et al., 2003), have not.

In the present sample, nearly three-quarters of respondents reported that they had previously engaged in at least one type of risky behavior. The most commonly reported risky behaviors were engaging in unprotected sex with someone other than one's regular partner and participating in recreational activities that carried a risk of severe injury or death; each of these was reported by approximately half of participants. Illegal drug use also was common, reported by nearly two in five participants. Self-injurious behavior was reported by one in five, and attempted suicide was reported by one in fourteen participants.

Compared to the USMC population as a whole, the present sample was somewhat younger, lower in rank, and more likely to be enlisted (vs. officers). This pattern of non-representativeness is common in research sampling military units during times of high operational tempo (e.g., see Hoge et al., 2004), and likely reflects the fact that higher-ranking personnel are more likely than their lower-ranking counterparts to be occupied with other activities during scheduled research times. Given that risky behavior is most common among young people, the present results may overestimate rates of risky behavior in the USMC as a whole. However, this bias may be counterbalanced by the likelihood that personnel who engage in the highest levels of risky behavior and those with the most severe psychiatric problems may be unavailable for participation due to attrition, disciplinary action, or injury, which would reduce the apparent prevalence of risky behavior in the sample, relative to its true prevalence in the USMC.

We found that rates of all risky behaviors were considerably higher during civilian life and declined significantly upon entering the military. Given that most of the risky behaviors considered here are more common at younger ages (Briere and Gil, 1998; Zuckerman, 2007), this decline may be partially attributable to maturation effects. It also is likely that differences between military and civilian environments contribute to reductions in risky behavior over time. For example, there is less tolerance of some types of risky behaviors in the military than in civilian environments. With respect to illegal drug use in particular, aggressive military policies have led to dramatic reductions over the past three decades (see Bray et al., 2006; Bray et al., 2003). It is therefore not surprising that illegal drug use showed the biggest declines from civilian to military life, from $39 \%$ to $5 \%$. Similar arguments might apply to reductions in other risky behaviors upon entering the military. Of course, the military and civilian worlds may differ in numerous other respects, as well, which also may influence the likelihood of risky behavior. For example, self-harm and suicide attempts might decrease upon entering the military because the military provides an increased sense of purpose, greater structure, or more social support than the average civilian context.

As civilians, non-deployers were significantly more likely than deployers to report four of five risky behaviors (the exception being suicide attempts) and all three psychiatric conditions. These findings are consistent with Haley's (1998) notion of the "healthywarrior effect". That is, in an atmosphere in which deployment is the norm, those who do not deploy are likely to have physical or psychological problems that prevent them from doing so. (For additional evidence supporting this effect see Bell et al., 2010.) However, our results indicate that pre-deployment differences between deployers and non-deployers in both risky behavior and psychiatric problems were most pronounced during the civilian time frame. Paradoxically, then, the present data suggest that, with respect to risky behavior and psychiatric problems, the "healthywarrior effect" may be substantially attenuated during military life, relative to civilian life.

Both within-subjects and between-group analyses revealed significant effects of deployment in increasing the likelihood of self-harm and risky recreation. In addition, between-groups (but not within-subjects) analyses indicated significant increases in the odds of illegal drug use among deployers relative to non-deployers, even after controlling for prior drug use. The magnitude of these 
changes was small relative to the changes that were observed between civilian and military (pre-deployment) life (see Fig. 1). It is important to note, however, that any increase in risky behavior over time occurs in opposition to the general decline in risky behavior that accompanies the aging process (Briere and Gil, 1998; Zuckerman, 2007). Because risky behavior is expected to decrease over time, any increase - even of apparently small magnitude - is noteworthy.

Of the two types of overtly self-destructive behavior examined, self-harm was significantly impacted by deployment whereas suicide attempts were not. Perhaps effects of deployment on suicide-related thoughts and behaviors would have been more readily apparent if we had assessed milder (and more prevalent) forms such as suicide-related ideation. Similarly, the inconsistent effects of deployment on illegal drug use may reflect the fact that this is an uncommon behavior, at least during military life. However, reduced statistical power resulting from low base rates cannot account for the null finding regarding deployment effects on engaging in unprotected sex with someone other than one's regular partner, as this was the most prevalent type of risky behavior in the present sample. It is not clear why risky sexual behavior, unlike risky recreational behavior, was not influenced by deployment. However, one might speculate that motivations unrelated to risktaking (e.g., sexual attraction, desire for intimacy) play a larger role in sexual behavior than in the other types of risky behavior examined. Also, unprotected sex is only one type of risky sexual behavior. In a review of characteristics predictive of sexual risktaking, Hoyle et al. (2000) found that unprotected sex was more weakly related to sensation seeking than other measures of sexual risk-taking, such as number of partners and risky encounters (e.g., sex with strangers). Perhaps other types of risky sexual behavior are more strongly influenced by deployment.

One important finding of the present research is that not all individuals were equally likely to demonstrate increases in risky behavior following deployment. As predicted, deployment effects on risky behaviors were largely restricted to individuals who had engaged in risky behaviors in the past. In fact, deployment did not have a significant effect on any of the five risky behaviors examined among individuals with no prior history of engaging in that type of risky behavior. In contrast, deployment significantly increased four of the five risky behaviors (the exception being suicide attempts) among individuals who had engaged in that behavior in the past. Thus, deployment does not appear to introduce new risk-taking behaviors among those who had not engaged in them previously, but rather to increase engagement in risky behaviors among those who had already engaged in them. This finding is consistent with the proposition that previous engagement in risky behavior may serve as a marker for problems or vulnerabilities that are likely to be exacerbated by deployment.

In addition to examining effects of deployment on risky and selfdestructive behaviors, this study considered a potential mediator of these associations: psychiatric problems, including depression, anxiety, and PTSD. Nearly one in four (23\%) of respondents reported that they had been told by a medical or mental health professional that they had one of these disorders. Depression was the most commonly reported problem (17\%), followed by anxiety (14\%), and PTSD (7\%). Despite the fact that respondents may underreport negative events due to social desirability concerns, we suspect that this figure may overestimate the percentage of personnel with psychiatric disorders. This may be the case because people - including health care professionals - often use the terms depression, anxiety, and PTSD in a nontechnical way, in reference to symptoms that do not meet diagnostic criteria. At the same time, however, people who experience significant symptoms of these disorders do not necessarily communicate those symptoms to a medical or mental health professional.
Therefore, although $23 \%$ may overestimate the number of personnel who have been diagnosed with one of these three psychiatric problems, it may underestimate the number of personnel who suffer symptoms associated with one of these disorders.

Preliminary analyses yielded evidence consistent with a mediating role of psychiatric conditions in the association between deployment and risky behavior. First, as for risky behavior, deployment was associated with increases in psychiatric problems. Specifically, during the current time frame, deployers were more likely than non-deployers to report all three psychiatric conditions, and among deployers, the likelihood of depression and PTSD (but not anxiety) increased significantly from pre- to post-deployment (cf. Hoge et al., 2004). In addition, psychiatric problems were positively associated with risky behavior. However, direct tests did not support a mediating role for psychiatric problems. Psychiatric conditions - particularly those within the current time frame - were associated with increased likelihood of risky behavior, above and beyond the effects of prior risky behavior. Interestingly, this was true for both overtly selfdestructive behaviors and behaviors that were less obviously intended to harm the self. However, controlling for prior and current psychiatric conditions did not substantially reduce the impact on current risky behavior of either the main effect of deployment or the deployment by prior behavior interaction.

As noted previously, our measures of psychiatric conditions are imprecise. Similarly, our measures of risky behaviors are each based on only one or two items. Reliability and precision would be enhanced by including multiple items to assess each construct. In addition, there is causal ambiguity in interpreting associations between current risky behaviors and current psychiatric conditions. Although this association could indicate that psychiatric issues are implicated in causing risky behavior, it is equally possible that engaging in risky behaviors is a marker of psychiatric problems. That is, people who report engaging in risky, or especially self-destructive, behaviors may be most likely to be labeled by medical or mental health professionals as having psychiatric issues. More generally, causal conclusions must be tempered by the fact that the present research is cross-sectional. Although our inclusion of both within-person and between-group comparisons and the replication of effects across both types of comparisons enhances the validity of the present conclusions, only longitudinal research can yield firm causal conclusions.

In addition, it is important to consider the possibility that response biases influenced the present results. The current study relied upon retrospective accounts of risky behaviors as well as psychiatric conditions. The most obvious retrospective bias - underreporting due to forgetting - cannot account for the present results, given that reports of risky behaviors were highest for the earliest period examined (i.e., as a civilian). Another possibility is that psychiatric conditions may distort memory, such that individuals suffering from depression or PTSD more readily recall traumatic events. However, findings regarding this hypothesis have been inconsistent (Fergusson et al., 2000; Wilson et al., 2008); moreover, generalizing this hypothesis to encompass the recall of risky behaviors is not straightforward. It also is possible that respondents underreported their risky behaviors and psychiatric problems due to concerns that such disclosures might negatively impact their careers. We do not think this is likely, however. All personnel were assured that their responses were anonymous and surveys were mailed to university researchers for processing, rather than being collected by military personnel. Previous research (Olson et al., 2004) has demonstrated that self-reports of negative events (specifically, childhood abuse) are at much higher levels under these conditions than in official surveys that would become part of the respondent's military record.

The present results suggest that post-deployment increases in psychiatric problems cannot account for increases in risky behavior 
following deployment. Because this is the first test of this hypothesis, these results should be replicated. Ideally, this replication will incorporate additional types of risky behavior beyond those considered here, as well as continuous measures of psychiatric symptoms, which are likely to be more valid, as well as more reliable and statistically powerful, than the single-item categorical measures used here. In addition to symptoms, further research should incorporate measures of other potential mediators, including habituation to pain and fear (Joiner's, 2005; Killgore et al., 2008) as well as desire to recapture the excitement or "adrenaline rush" frequently experienced during deployment (Vaughan, 2006). In addition, given evidence that symptoms are more strongly predicted by combat exposure than by deployment per se (e.g., Hotopf et al., 2006), it would be instructive to examine the effects of specific combat experiences on risky post-deployment behavior. Although the present study examined broad patterns of change in risky behavior before and after the first combat deployment, future research might examine whether effects of deployment or combat exposure on risky behavior vary over the course of the deployment cycle. Some evidence suggests that mental health problems following return from combat deployment peak four to six months after return (Bliese et al., 2007; Grieger et al., 2006; Hoge et al., 2006); the same may be true for risky behavior. In addition, future research should examine whether post-deployment increases in risk-taking are meaningfully influenced by the number or duration of deployments experienced.

Because the present findings indicated that personnel with a history of risky behavior were most likely to exhibit increases in risky behavior following deployment, it might be advantageous to screen potential deployers for a prior history of risky behavior. This would allow for identification of personnel at heightened risk of experiencing adverse consequences of deployment. However, as discussed previously, military personnel are often reluctant to disclose negative personal information when that information will become part of their official records (Olson et al., 2004).

Even if it were possible to obtain accurate information about history of risky behavior, however, restricting the combat deployments of personnel who have engaged in risky behavior in the past might be ill-advised. There is some evidence that high sensation seekers - who are prone to engage in a range of risky behaviors (Zuckerman, 2007) - may be particularly well-suited to enduring the stresses and hardships associated with deployment. Military personnel who are higher in risk-taking are more likely to receive medals for heroism (Neria et al., 2000; Wansink et al., 2008) and are perceived by their peers as being more effective in combat (Himmelstein and Blaskovics, 1960). In a sample of former prisoners of war, Solomon et al. (1995) found that high sensation seekers, relative to low sensation seekers, exhibited more adaptive coping strategies during captivity, displayed fewer feelings of helplessness and loss of control, and had better psychological outcomes two decades later. Because the same overt risky behaviors might imply either greater vulnerability to the stresses of deployment or greater ability to deal with those stresses, further research is necessary to determine the utility of using previous engagement in risky behaviors as a tool to aid in deployment decisions. Given that reducing adverse reactions to deployment has enormous benefits for the individual, for the military, and for society at large, further exploration of these issues is clearly warranted.

\section{Contributors}

Cynthia J. Thomsen was primarily responsible for conceptualizing the hypotheses and the analytic strategy for this study, conducting the statistical analyses and writing the research report. In addition, she participated in the design of the overarching project and the selection and development of measures.
Valerie Stander was primarily responsible for conceptualizing the overarching project, designing the survey, and obtaining funding for this study. She supervised data collection efforts, contributed to the conceptualization of the hypotheses and analytic strategy for the present study, and participated in revisions of the manuscript.

Stephanie McWhorter was involved in design of the overarching project, contributed to data collection and formatted the survey instrument. In addition, she participated in survey coding and in revisions of the manuscript.

Mandy M. Rabenhorst assisted with conducting literature searches, supervised data entry and data cleaning, and contributed to revisions of the manuscript.

Joel S. Milner supervised the receipt of data and made substantial contributions to revisions of the manuscript.

All authors contributed to and have approved the final manuscript.

\section{Role of the funding source}

Funding for this study was provided by the Office of Prevention and Intervention (OPI), Headquarters Marine Corps, Manpower, under Work Unit No. 60202. The OPI had no further role in study design; in the collection, analysis, or interpretation of data; or in the writing of the report. However, OPI personnel reviewed this manuscript and approved its release for publication.

\section{Conflict of interest}

None of the authors declare any potential or actual conflict of interest that could influence or be perceived to influence the design, analysis, or reporting of this study.

\section{Acknowledgements}

The views expressed in this article are those of the authors and do not reflect the official policy or position of the Department of the Navy, Department of Defense, or the U.S. Government. This research has been conducted in compliance with all applicable federal regulations governing the protection of human subjects in research. The authors acknowledge the generous support of the project sponsors, Mr. Cruz Martinez and Mr. Gregory Goldstein, Headquarters Marine Corps Office of Prevention and Intervention. Sincere appreciation also is expressed to the command leadership of Marine Corps Air Station Yuma, 1st Marine Logistics Group, Camp Pendleton, and 1st Marine Division, Camp Pendleton. Finally, we are greatly indebted to the U.S. Marines who participated in this study.

\section{References}

Bell NS, Amoroso PJ, Williams JO, Yore MM, Engel Jr CC, Senier L, et al. Demographic physical and mental health factors associated with deployment of U.S. Army soldiers to the Persian Gulf. Military Medicine 2010;175:227-37.

Bliese PD, Wright KM, Adler AB, Thomas JL, Hoge CW. Timing of postcombat mental health assessments. Psychological Services 2007;4:141-8.

Boscarino JA. Post-traumatic stress and associated disorders among Vietnam veterans: the significance of combat exposure and social support. Journal of Traumatic Stress 1995;8:317-36.

Bray RM, Hourani LL, Olmsted KLR, Witt M, Brown JM, Pemberton MR, et al. 2005 Department of defense survey of health related behaviors among military personnel. (RTI international Rep. No. RTI/7841/106-FR). Research Triangle Park NC: Research Triangle Institute; 2006.

Bray RM, Hourani LL, Rae KL, Dever JA, Brown JM, Vincus AA, et al. 2002 Department of defense survey of health related behaviors among military personnel (RTI international Rep. No. RTI/7841/006-FR). Research Triangle Park, NC: Research Triangle Institute; 2003.

Brenner LA, Gutierrez PM, Cornette MM, Betthauser LM, Bahraini N. A qualitative study of potential suicide risk factors in returning combat veterans. Journal of Mental Health Counseling 2008;30:211-25

Bricknell MC, Amoroso PJ, Yore MM. What is the risk associated with being a qualified military parachutist? Occupational Medicine 1999;49:139-45. 
Briere J, Gil E. Self-mutilation in clinical and general population samples: prevalence, correlates, and functions. American Journal of Orthopsychiatry 1998;68:609-20.

Browne T, Iversen AC, Hull L, Workman L, Barker C, Horn O, et al. How do experiences in Iraq affect alcohol use among male UK armed forces personnel? Occupational and Environmental Medicine 2008;65:628-33.

Bryan CJ, Cukrowicz KC, West CL, Morrow CE. Combat experience and the acquired capability for suicide. Journal of Clinical Psychology 2010;66:1044-56.

Calhoun PS, Elter JR, Jones ER, Kudler HS, Straits-Troster K. Hazardous alcohol use and receipt of risk reduction counseling among U.S. veterans of the wars in Iraq and Afghanistan. Journal of Clinical Psychiatry 2008;69:1686-93.

Catlin Boehmer TK, Flanders WD, McGeehin MA, Boyle C, Barrett DH. Postservice mortality in Vietnam veterans: 30-year follow-up. Archives of Internal Medicine 2004:164:1908-16.

Centers for Disease Control. Current trends: postservice mortality among Vietnam veterans. Morbidity and Mortality Weekly Report 1987;36:61-4.

Fear NT, Iversen AC, Chatterjee A, Jones M, Greenberg N, Hull L, et al. Risky driving among regular armed forces personnel from the United Kingdom. American Journal of Preventive Medicine 2008;35:230-6.

Fergusson DM, Horwood LJ, Woodward LJ. The stability of child abuse reports: a longitudinal study of the reporting behaviour of young adults. Psychological Medicine 2000;30:529-44.

Grieger TA, Cozza SJ, Ursano RJ, Hoge C, Martinez PE, Engel CC, et al. Posttraumatic stress disorder and depression in battle-injured soldiers. American Journal of Psychiatry 2006;163:1777-83.

Haley RW. Point: bias from the "healthy-warrior effect" and unequal follow-up in three government studies of health effects of the Gulf War. American Journal of Epidemiology 1998;148:315-23.

Hall DP. Stress, suicide, and military service during Operation Uphold Democracy Military Medicine 1996;161:159-62.

Hansen-Schwartz J, Jessen G, Andersen K, Jørgensen HO. Suicide after deployment in UN peacekeeping missions-A Danish pilot study. Crisis 2002;23:55-8.

Himmelstein P, Blaskovics TL. Prediciton of an intermediate criterion of combat effectiveness with a biographical inventory. Journal of Applied Psychology 1960;44:166-8.

Hoge CW, Auchterlonie JL, Milliken CS. Mental health problems, use of mental health services, and attrition from military service after returning from deployment to Iraq or Afghanistan. Journal of the American Medical Association 2006;295:1023-32.

Hoge CW, Castro CA, Messer SC, McGurk D, Cotting DI, Koffman RL. Combat duty in Iraq and Afghanistan, mental health problems, and barriers to care. New England Journal of Medicine 2004;351:13-22.

Hotopf M, Hull L, Fear NT, Browne T, Horn O, Iversen A, et al. The health of UK military personnel who deployed to the 2003 Iraq War: a cohort study. Lancet 2006:367:1731-41.

Hoyle R, Fejfar MC, Miller JD. Personality and sexual risk-taking: a quantitative review. Journal of Personality 2000;68:1203-31.

Jobe JB, Holgate SH, Scrapansky TA. Risk taking as motivation for volunteering for a hazardous experiment. Journal of Personality 1983;51:95-107.

Joiner TE. Why people die by suicide. Cambridge, MA: Harvard University Press; 2005

Kang HK, Bullman TA, Macfarlane GJ, Gray GC. Mortality among US and UK veteran of the Persian Gulf War: a review. Occupational and Environmental Medicine 2002;59:794-9.

Kaplan MS, McFarland BH, Huguet N. Firearm suicide among veterans in the genera population: findings from the national violent death reporting System. Journa of Trauma-Injury Infection and Critical Care 2009:67:503-7.

Killgore WDS, Cotting DI, Thomas JL, Cox AL, McGurk D, Vo AH, et al. Post-combat invincibility: violent combat experiences are associated with increased risktaking propensity following deployment. Journal of Psychiatric Research 2008; 42:1112-21.

Klonsky ED. The functions of deliberate self-injury: a review of the evidence. Clincial Psychology Review 2007;27:226-39.

Klonsky ED, Oltmanns TF, Turkheimer E. Deliberate self-harm in a nonclinical population: prevalence and psychological correlates. American Journal of Psychiatry 2003;160:1501-8.

Knapik JJ, Marin RE, Grier TL, Jones BH. A systematic review of post-deployment injury-related mortality among military personnel deployed to conflict zones. BMC Public Health 2009;9.
Koenen KC, Lyons MJ, Goldberg J, Simpson J, Williams WM, Toomey R, et al. Cotwin control study of relationships among combat exposure, combat-related PTSD, and other mental disorders. Journal of Traumatic Stress 2003;16: 433-8.

Laye-Gindhu A, Schonert-Reichl KA. Nonsuicidal self-harm among community adolescents: understanding the "whats" and "whys" of self-harm. Journal of Youth and Adolescence 2005;34:447-57.

Leigh BC, Temple MT, Trocki KF. The relationship of alcohol use to sexual activity in a U.S. national sample. Social Science Medicine 1994;39:1527-35.

Marine Corps Community Services. Marine Corps Community Services demographics update. Retrieved March 18, 2008, from http://www.usmc-mccs. org/aboutmccs/downloads/pom/Demographics\%20Update_Dec2007.pdf 2007, December.

Matsumoto T, Yamaguchi A, Asami T, Okada T, Yoshikawa K, Hirayasu Y. Characteristics of self-cutters among male inmates: association with bulimia and dissociation. Psychiatry and Clinical Neurosciences 2005;59:319-26.

Muehlenkamp JJ, Gutierrez PM. Risk for suicide attempts among adolescents who engage in non-suicidal self-injury. Archives of Suicide Research 2007;11: 69-82.

Nell V. Why young men drive dangerously: implications for injury prevention. Current Directions in Psychological Science 2002;11:75-9.

Neria Y, Solomon Z, Ginzburg K, Dekel R. Sensation seeking, wartime performance, and long-term adjustment among Israeli war veterans. Personality and Individual Differences 2000;29:921-32.

O'Toole BI, Cantor C. Suicide risk factors among Australian Vietnam era draftees. Suicide and Life-Threatening Behavior 1995;25:475-88.

Olson CB, Stander VA, Merrill LL. The influence of survey confidentiality and construct measurement in estimating rates of childhood victimization among Navy recruits. Military Psychology 2004;16:53-69.

Silverman MM, Berman AL, Sanddal ND, O'Carroll PW, Joiner Jr TE. Rebuilding the tower of Babel: a revised nomenclature for the study of suicide and suicidal behaviors Part 2: suicide-related ideations, communications, and behaviors. Suicide and Life-Threatening Behavior 2007;37:264-77.

Solomon Z, Ginzburg K, Neria Y, Ohry A. Coping with war captivity: the role of sensation seeking. European Journal of Personality 1995;9:57-70.

Stea JB, Anderson MA, Bishop JM, Griffith LJ. Behavioral health force protection: optimizing injury prevention by identifying shared risk factors for suicide, unintentional injury, and violence. Military Medicine 2002;167:944-9.

Thoresen S, Mehlum L. Risk factors for fatal accidents and suicides in peacekeepers: is there an overlap? Military Medicine 2004;169:988-93.

Thoresen S, Mehlum L, Moller B. Suicide in peacekeepers: a cohort study of mortality from suicide in 22,275 Norwegian veterans from international peacekeeping operations. Social Psychiatry and Psychiatric Epidemiology 2003; 38:605-10.

Vaughan D. Risky business. Today's Officer; 2006:21-4.

Wansink B, Payne CR, van Ittersum K. Profiling the heroic leader: empirical lessons from combat-decorated veterans of World War II. The Leadership Quarterly 2008;19:547-55.

Whitlock J, Eckenrode J, Silverman D. Self-injurious behaviors in a college population. Pediatrics 2006;117:1939-48.

Whitlock J, Knox KL. The relationship between self-injurious behavior and suicide in a young adult population. Archives of Pediatric and Adolescent Medicine 2007; 161:634-40.

Wilson JP, Jones M, Hull L, Hotopf M, Wessely S, Rona RJ. Does prior psychological health influence recall of military experiences? A prospective study. Journal of Traumatic Stress 2008;21:385-93.

Wojcik BE, Akhtar FZ, Hassell LH. Hospital admissions related to mental disorders in U.S. Army soldiers in Iraq and Afghanistan. Military Medicine 2009;174: 1010-8.

Wong A, Escobar M, Lesage A, Loyer M, Vanier C, Sakinofsky I. Are UN peacekeepers at risk for suicide? Suicide and Life-Threatening Behavior 2001;31:103-12.

Zhang J, McKeown RE, Hussey JR, Thompson SJ, Woods JR. Gender differences in risk factors for attempted suicide among young adults: findings from the third national health and nutrition examination survey. Annals of Epidemiology 2005;15:167-74.

Zuckerman M. Sensation seeking and risky behavior. Washington, DC: American Psychological Association; 2007. 